\title{
Long-term azathioprine in rheumatoid arthritis: a double-blind study
}

\author{
M. DE SILVA AND B. L. HAZLEMAN \\ From the Department of Rheumatology, Addenbrooke's Hospital, Hills Road, Cambridge CB2 $2 Q Q$
}

SUMMARY Several studies have demonstrated the beneficial effect of azathioprine in rheumatoid arthritis. But fears have been expressed about the possible mutagenic and teratogenic effects of prolonged use. If the drug could be withdrawn once remission is achieved, and this remission be then maintained with other agents, the possible complications of long-term therapy might be avoided. A double-blind controlled study was carried out over 8 months in 32 patients receiving long-term azathioprine therapy for rheumatoid arthritis. Substitution of placebo for active drug resulted in clinical deterioration.

Several controlled studies have shown that azathioprine suppresses disease activity in rheumatoid arthritis. ${ }^{1-3}$ Since this treatment may not produce a lasting remission, long-term administration can be expected in many instances. The potential adverse effects of prolonged use, including bone marrow suppression, susceptibility to infection, and a tendency to develop malignant tumours, have discouraged its use at an earlier stage of the disease, when it may exert a disease modifying effect.

If azathioprine can be withdrawn once remission has been achieved and this remission then maintained with other agents, long-term therapy and its attendant hazards may be avoided. At present there are insufficient data to ascertain whether this approach is practicable. We report the results of a controlled double-blind study over a period of 8 months on 32 patients with rheumatoid arthritis on long-term azathioprine, when placebo was substituted for the active drug.

\section{Patients and methods}

Thirty-two patients were allotted at random to 2 groups; 18 received placebo and 14 continued with azathioprine. The 2 groups were well matched for age, sex, disease duration, serology, and functional capacity. The duration of treatment with azathioprine and details of treatment are given in Table 1. Most patients required anti-inflammatory agents and analgesics in addition to azathioprine. Twenty-one patients, 12 in the placebo group and 9

Accepted for publication 9 January 1981

Correspondence to Dr M. de Silva.
Table 1 Details of patients and treatment

\begin{tabular}{|c|c|c|c|}
\hline & & Placebo & Azathioprine \\
\hline \multicolumn{2}{|l|}{$\begin{array}{l}\text { No. of patients } \\
\text { Male/female }\end{array}$} & $\begin{array}{l}18 \\
3 / 15\end{array}$ & $\begin{array}{l}14 \\
4 / 10\end{array}$ \\
\hline Age in years: & $\begin{array}{l}\text { mean } \\
\text { range }\end{array}$ & $\begin{array}{l}62 \\
29-76\end{array}$ & $\begin{array}{l}59 \\
42-72\end{array}$ \\
\hline Disease duration in years: & $\begin{array}{l}\text { mean } \\
\text { range }\end{array}$ & $\begin{array}{l}13 \cdot 8 \\
5-38\end{array}$ & $\begin{array}{l}18 \cdot 2 \\
5-50\end{array}$ \\
\hline \multicolumn{2}{|l|}{$\begin{array}{l}\text { Sero }+\mathrm{ve} /-\mathrm{ve} \\
\text { Duration of treatment with }\end{array}$} & $12 / 6$ & $9 / 5$ \\
\hline azathioprine: (yr) & $\begin{array}{l}\text { mean } \\
\text { range }\end{array}$ & $\begin{array}{l}6 \cdot 1 \\
2-11\end{array}$ & $\begin{array}{l}6 \cdot 6 \\
3-12\end{array}$ \\
\hline Dose of azathioprine $\mathrm{mg} / \mathrm{kg} /$ day: & $\begin{array}{l}\text { mean } \\
\text { range }\end{array}$ & $\begin{array}{l}2 \cdot 42 \\
1 \cdot 08-4 \cdot 71\end{array}$ & $\begin{array}{l}2 \cdot 71 \\
0 \cdot 82-4 \cdot 80\end{array}$ \\
\hline \multicolumn{2}{|l|}{ No. on gold injections } & 12 & 9 \\
\hline No. on steroids: & $\mathrm{rH}$ inj. & $\begin{array}{l}2 \\
2\end{array}$ & $\begin{array}{l}2 \\
3\end{array}$ \\
\hline
\end{tabular}

in the azathioprine group, had been on a combination of gold and azathioprine. Patients were stabilised on the minimum effective dosages of their drugs for several months before the study began. Changes only in analgesic requirement were allowed, and these were noted.

Clinical and laboratory assessments were made at the start of the study and after $8,16,24$, and 32 weeks of therapy. Clinical assessment consisted of day and night pain on a 5 -point scale ( $0-4)$, morning stiffness $( \pm 20 \mathrm{~min})$, and the patient's and clinician's general evaluation of the response to therapy. Measurements included articular index (modified Ritchie, maximum score 78) and grip strength (mmHg). Laboratory assessment included: (1) haemoglobin, leucocyte count and differential, and erythrocyte sedimentation rate; (2) plasma proteins, bilirubin, and transaminase; (3) immunoglobulin 
quantitation (IgA, IgG, and IgM); (4) acute phase reactants $\left(\alpha_{1}\right.$ antitrypsin, orosomucoid, and haptoglobin); and (5) urine analysis and microscopy.

At the initial assessment rheumatoid factor, antinuclear factor, and serum $B_{12}$ and red blood cell folate were estimated.

Side effects elicited by a standard questionnaire were recorded at each visit. Patients were to be withdrawn if there was unacceptable deterioration in symptoms, in the presence of severe intercurrent illness, if there were serious biochemical or haematological abnormalities, or in the case of major surgery or pregnancy.

\section{Results}

The histograms (Figs. 1 and 2) compare pain and morning stiffness at 8 and 32 weeks in the 2 groups of patients. For pain a change of 1 unit was considered significant and similarly a change of 20 minutes for morning stiffness. Patients in the azathioprine group tended to remain unchanged, whereas in the placebo group the trend was to deteriorate. There was no significant difference between the 2 groups with respect to grip strength and articular index. For pain the deterioration became statistically significant (Student's $t$ test) at $\mathbf{8}$ weeks and for morning stiffness at 16 weeks (Tables 2 and 3).

The patient's and clinician's general assessments
Table 2 Comparison of mean $( \pm S E M)$ pain scores (scale 0-4) between patients on azathioprine and placebo

\begin{tabular}{clll}
\hline Week & \multicolumn{2}{c}{ Mean \pm SEM } & $\begin{array}{c}\text { Statistical significance } \\
(p)\end{array}$ \\
\cline { 2 - 3 } & Azathioprine & Placebo & \\
& & & \\
\hline 0 & $1.4 \pm 0.3$ & $1.8 \pm 0.2$ & NS \\
8 & $1.4 \pm 0.2$ & $1.9 \pm 0.2$ & $<0.05$ \\
16 & $1.3 \pm 0.3$ & $1.9 \pm 0.2$ & $<0.05$ \\
24 & $0.9 \pm 0.3$ & $1.9 \pm 0.2$ & $<0.01$ \\
32 & $1.2 \pm 0.3$ & $1.9 \pm 0.3$ & $<0.03$
\end{tabular}

NS $=$ not significant

Table 3 Comparison of mean $( \pm S E M)$ duration of morning stiffness (minutes) between patients on azathioprine and placebo

\begin{tabular}{|c|c|c|c|}
\hline \multirow[t]{2}{*}{ Week } & \multicolumn{2}{|l|}{$M e a n \pm S E M$} & \multirow{2}{*}{$\begin{array}{c}\text { Statistical significance } \\
(p)\end{array}$} \\
\hline & Azathioprine & Placebo & \\
\hline $\begin{array}{r}0 \\
8 \\
16 \\
24 \\
32\end{array}$ & $\begin{array}{l}43 \cdot 9 \pm 25 \cdot 3 \\
34 \cdot 3 \pm 17 \cdot 1 \\
18 \cdot 8 \pm 6 \cdot 2 \\
16 \cdot 4 \pm 5 \cdot 9 \\
25 \cdot 9 \pm 11 \cdot 1\end{array}$ & $\begin{array}{r}40 \cdot 0 \pm 13 \cdot 2 \\
82 \cdot 9 \pm 26 \cdot 1 \\
100 \cdot 3 \pm 32 \cdot 5 \\
70 \cdot 7 \pm 26 \cdot 0 \\
100 \cdot 9 \pm 41 \cdot 7\end{array}$ & $\begin{array}{l}\text { NS } \\
\text { NS } \\
<0.03 \\
<0.05 \\
<0.05\end{array}$ \\
\hline
\end{tabular}

NS $=$ not significant.

at the time of withdrawal or at the end of 32 weeks showed that only 1 patient in the azathioprine group deteriorated compared with 12 in the placebo group.

In the laboratory assessments the only significant

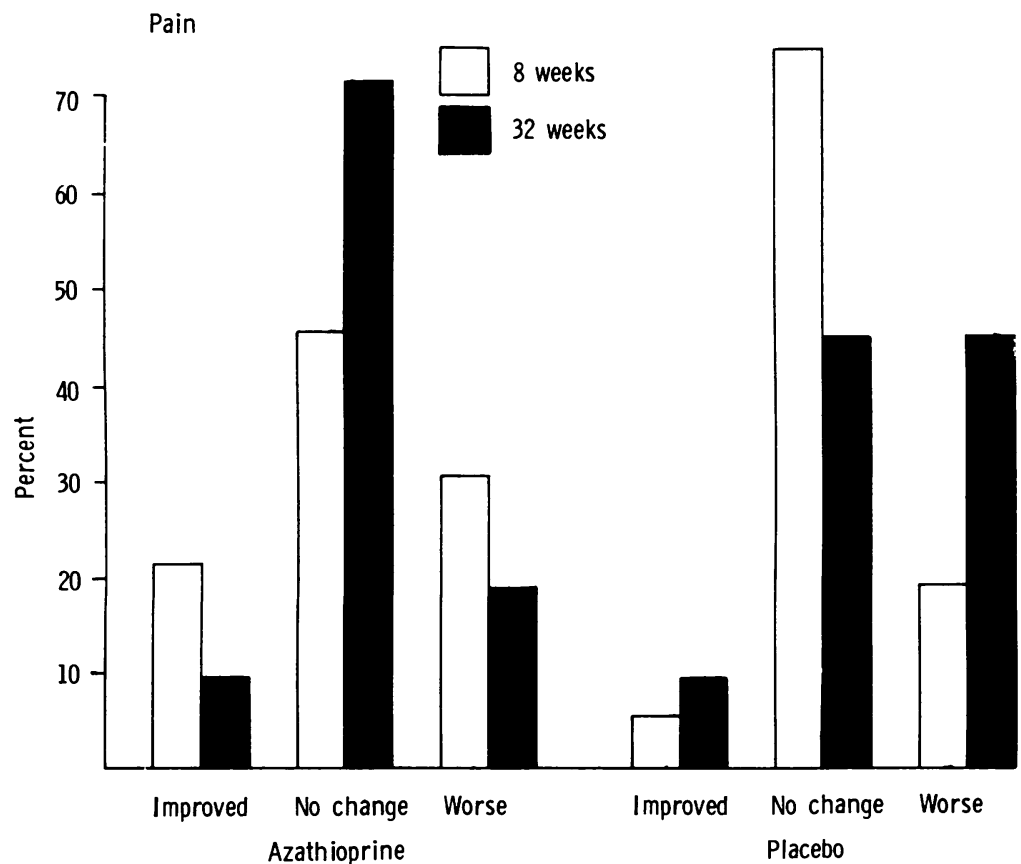

Fig. 1 Histograms showing the status at 8 and 32 weeks of patients in the azathioprine and placebo groups. 
Morning Stiffness

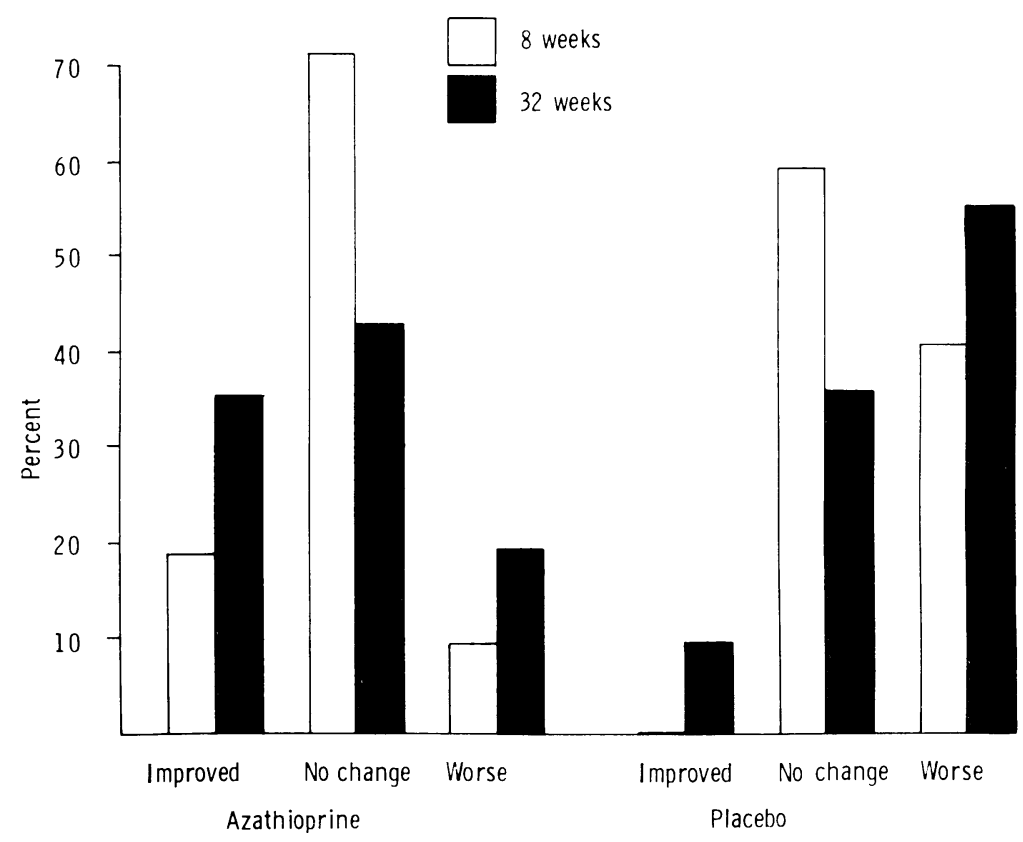

Fig. 2 Morning stiffiness: histograms showing the status at \& and 32 weeks of patients in the azathioprine and placebo groups.

differences between the 2 groups occurred for total white cell count at 24 and 32 weeks and for orosomucoid at 32 weeks, $\mathrm{p}<0.05$ (Student's $t$ test). Seven patients were noted to have a macrocytosis during the course of the study. Two of these patients had a low red cell folate and one a low $B_{12}$ level. Bone marrow examination and Dicopac tests on these patients were normal. Clinical deterioration was the reason for withdrawal in 6 patients in the placebo group; the 3 withdrawals in the azathioprine group were for other reasons. The reasons for withdrawal are shown in Table 4.

These results therefore show that withdrawal of azathioprine has a detrimental effect on disease activity. Patients in the placebo group continued to deteriorate up to 32 weeks, at which stage a further 5 patients had to be started again on azathioprine. Of the 32 patients who participated in this study $11 \mathrm{had}$

\section{Table 4 Reasons for withdrawal}

Azathioprine $3 / 14-21 \%$
1 Carcinoma of tonsil
1 Major surgery-bilateral total hip replacement
1 Pancytopenia
Placebo $\quad 7 / 18-39 \%$
6 Clinical deterioration
1 Uncontrolled itching

been on azathioprine and 21 on a combination of azathioprine and gold. Of those on combination therapy placebo was substituted for azathioprine in 12 and 9 continued on the active drug. Seven patients in the placebo group deteriorated despite continuing on gold, whereas none of the 9 who continued on combination therapy deteriorated.

\section{Discussion}

The results of our study, which are in agreement with a previous study by Hunter et al., ${ }^{1}$ show that azathioprine continues to exert a beneficial effect in rheumatoid arthritis over a prolonged period in a small group of patients. Our findings differ from those of Thomas et al., " who in a retrospective study of patients with rheumatoid arthritis reported more treatment failures, a diminished steroid-sparing effect and a greater number of toxic reactions, and lowered patient acceptability of azathioprine. Harris et al. ${ }^{6}$ however, found that the steroid-sparing effect of azathioprine persisted 'for some time' after it was discontinued. This evidence was based on a small study.

The timing of the response to azathioprine is unlike that observed with anti-inflammatory agents but resembles more the slow response associated 
with disease-modifying agents such as gold. Likewise, relapse on withdrawal may also be expected to be delayed, as shown in our group of patients. Studies evaluating slow-acting drugs like azathioprine should be conducted over long periods; this would also minimise the effect of natural remissions and exacerbations characteristic of rheumatoid arthritis.

The patients in this study were included in a group of 214 patients treated with cytotoxic drugs over an 11-year period. ${ }^{7}$ Although neoplasia were more common in this group as a whole, patients on azathioprine had an incidence similar to that of the control population. Our study, like many others, ${ }^{46}$ confirms a low incidence of adverse effects.

Most patients in this study had been suffering from severe active rheumatoid arthritis requiring treatment with corticosteroids. Gold was used for its steroidsparing effect and azathioprine added, initially in a high dose of $5 \mathrm{mg} / \mathrm{kg} /$ day on 5 or 6 days of the week, in the hope that gold toxicity might be reduced. Some patients had received azathioprine for as long as 12 years. The mean daily dose of azathioprine in our present study was $2.6 \mathrm{mg} / \mathrm{kg} / \mathrm{day}$, the drug being administered only on 5 days of the week.

Hunter et al. ${ }^{4}$ compared 2 dosage regimens (mean $1.4 \mathrm{mg} / \mathrm{kg} /$ day). They found that both half dose $(1-1 \cdot 25 \mathrm{mg} / \mathrm{kg} /$ day) and full dose $(2-2 \cdot 5 \mathrm{mg} / \mathrm{kg} /$ day $)$ exerted a beneficial effect in severe rheumatoid arthritis. Further studies are required to establish the safest effective dose.

Our results show that in rheumatoid arthritis azathioprine is beneficial in long-term therapy.
Withdrawal results in an exacerbation of disease activity even when patients continue to receive other anti-rheumatic agents, such as gold and nonsteroidal anti-inflammatory drugs. The combination of gold and azathioprine appears to be beneficial in certain patients.

The authors thank the Wellcome Research Laboratories for supplying the azathioprine and placebo tablets, the Arthritis and Rheumatism Council for their support, and the Departments of Clinical Biochemistry and Haematology, Addenbrooke's Hospital.

\section{References}

1 Mason R M, Currey H L F, Barnes C G, et al. Azathioprine in rheumatoid arthritis. $\mathrm{Br} \mathrm{Med} J \mathrm{1969}$; i: 420-2.

2 Urowitz M B, Gordon D A, Smythe H A, et al. Azathioprine in rheumatoid arthritis. A double-blind cross-over study. Arthritis Rheum 1973; 16: 411-8.

3 Currey H L F, Harris J, Mason R M, et al. Comparison of azathioprine, cyclophosphamide, and gold in the treatment of rheumatoid arthritis. $B r \operatorname{Med} J$ 1974; iii: 763-6.

4 Hunter T, Urowitz M B, Gordon D A, et al. Azathioprine in rheumatoid arthritis: a long-term follow-up study. Arthritis Rheum 1975; 18: 15-20.

5 Thomas M H, Bergen N, Phillips V K, et al. Immunosuppressive therapy in rheumatic diseases. A retrospective study. Ohio State Med J 1975; 71 : 624-6.

6 Harris J, Jessop J D, Chaput de Saintonge M D, Further experience with azathioprine in rheumatoid arthritis. Br Med J 1971; iv: 463-4.

7 Lewis P, Hazleman B L, Hanka R, Roberts S. Cause of death in patients with rheumatoid arthritis with particular reference to azathioprine. Ann Rheum Dis 1980; 39: 457-61. 